\title{
Combinations to Reflect All
}

\section{Nations}

\author{
Economic and symbolic capital in diverse children's fiction
}

\section{Megan Dennis}

Meggie is the Editorial Assistant at David Fickling Books, where she has worked with authors such as award-winning Jenny Downham and Lisa Williamson and been involved in the launch of Philip Pullman's The Secret Commonwealth. She completed the MA in Publishing at Oxford Brookes University in 2019; her dissertation (sponsored by the Penguin Collectors' Society) focused on Kaye Webb's legacy at Puffin encouraging children to read for pleasure. Meggie graduated with First Class Honours in English from the University of Exeter, where her dissertation compared Paradise Lost and the Harry Potter series.

18039899@brookes.ac.uk

As Children's Laureate 2013-2015, Malorie Blackman raised awareness of the lack of racial diversity in children's fiction. Underrepresentation of ethnic minorities in fiction and the publishing industry's infrastructure is a severe problem in the world of children's books, as illuminated by research into the publishing environment of the past 15 years, and the books populating current bestseller charts. Pierre Bourdieu's theory of economic and symbolic capital is important to understanding how diversity is highlighted in the contemporary literary field, but his polarization of the different form of capital as motivation for creating art is reductive. Storytelling is about combining voices and experiences, and publishers can, and should, combine economic and symbolic motivations in publishing diverse fiction for children. Publishing a book because it will be successful economically and because it is the right thing to do are not mutually exclusive; in publishing diverse children's fiction, both motives can and should inspire us.

Keywords: Children's Laureate, children's fiction, diversity, symbolic capital, economic capital, paratext 


\section{Introduction}

'There were always too many people ready to set my limits for me,' said author Malorie Blackman, OBE, speaking of her childhood (Coats, 2014, p. 6). Feeling confined to predetermined paths based on her ethnicity, she was told when considering jobs that 'black people become secretaries' (Peacock, 2014). Blackman broke through these limits, becoming a bestselling children's author and pushing past further constraints from adults who told her, when she started her career, that white children would not want to read about black characters. However, Blackman's books exist in a realm of children's fiction where there are still limits upon the kinds of books that are published and the different types of capital perceived to be invested in them. Storytelling's power comes from pushing limits and moving beyond what we believe to be true or possible, while simultaneously teaching us about ourselves and the world we do live in. This duality of fantasy and fact is especially important in children's fiction, which shapes the way young people see the world and themselves. Blackman's life shows how breaking limits is rewarding; similarly, to expand the limits on children's fiction to make it more representative, and to develop and combine the kind of capitals invested in diverse children's books, is also morally, economically, and symbolically rewarding.

One way Blackman broke free from 'challenges and opposition from some editors, booksellers and librarians' (Coats, 2014, p. 7), reluctant to support her books because of their focus on ethnicity, was when she took on 'the most inspiring post in children's literature' (Blake, 2019). As Children's Laureate from 2013 to 2015, Blackman focused during her tenure on emphasizing the importance of diversity. She described as a child " never once read[ing] a book that featured a black child [despite being a prolific reader]", which left her feeling "totally invisible"' (Ward, 2013). To combat this as Children's Laureate, Blackman established the annual Young Adult (YA) Literature Convention, edited an inclusive YA anthology of short stories covering disability and LGBTQ+ themes, supported libraries, and was consistently vocal about racial representation, to try to make it easier for marginalized children to access representative fiction.

Laureates are traditionally revered and praised; Children's Laureates are similarly respected in the literary field, deemed 'the perfect ambassadors for children's literature' (Walker, 2019). However, despite having supposedly perfect ambassadors, who have often tried to improve the diversity situation, British children are still inaccurately represented in fiction. In July 2018, the Centre for Literacy in Primary Education (CLPE) published a report analysing ethnic representation in children's literature. It statistically confirmed the existence of a monoculture in children's publishing, often anecdotally acknowledged by writers, including Blackman ('white adults sometimes think that if a black child's on the [book] cover it is perhaps not for [their children]' [Ward, 2013]). The report showed that only four per cent of children's books published in 2017 included black, Asian, or other ethnic minority (BAME) characters, and only one per cent featured a BAME protagonist, despite 32 per cent of pupils of compulsory school age in England at that time having minority ethnic origins (CLPE, 2018, 5). Publishers need to take note of voices such as Blackman's and this shocking statistical evidence and ensure that books published today are not limiting and instead value multiplicity: that they tell stories of children from a range of cultures and ethnic backgrounds. Not only would this enable more children to see themselves reflected in literature, which has essential moral value, but, from a more purely economic perspective, by publishing books that only a limited market can relate to, publishers are missing out on vast potential audiences and therefore revenue. Publishers must combine stories from a global range of cultures in order to break free from a limiting canon of white-centred fiction.

\section{Forms of capital and the importance of publishers combining them}

Stories consist of combinations of voices, characters, and experiences; the market of child readers combines children from different backgrounds; and in order for 'reading and reflection [to] multiply [readers'] experience' (Gibbon quoted in McMaster, 2013, p. 45) publishers need to invest a combination of forms of capital in diverse children's fiction (children who are currently well represented in fiction need to read and learn about underrepresented categories of people, too). Economic capital (financial value a book can accumulate) and symbolic capital (cultural prestige and reputation) underpin publishing activity; Pierre Bourdieu argues that the structure of the publishing field is shaped above all by 
the differential distribution' (1996, p. 9, emphasis mine) of these forms of capital. He consistently contrasts the two forms of capital as inspiration for cultural production, arguing that art is produced either for economic gain or simply for art's sake-and that it is these forms of capital that are particularly important in determining [a publisher's] competitive position' (1996, p. 9). The rise of conglomerate publishers has seen companies' competitive positions altered as corporate giants become more dramatically contrasted with smaller independent houses. Although there is an apparent polarization between conglomerates and independent publishers, so that 'the large corporations become the dominant players' (Thompson, 2010, p. 187), when it comes to diversity in fiction smaller houses are beginning to thrive and become trailblazers.

The independent publisher Knights Of (KO) was established in October 2017. Founded by Aimée Felone and David Stevens (who both previously worked at Scholastic, so had experience accruing economic and symbolic capital at a larger publisher), KO is explicit in its focus on publishing commercial and inclusive children's books featuring children from ethnic minorities or with disabilities. Although small, with significantly less economic capital than its conglomerate competitors, KO's deliberate effort to increase diversity and representation in children's fiction has gained them significant symbolic capital. Stevens and Felone were named Bookseller Rising Stars 2018, endowing KO with prestige, and Felone was a featured speaker at London Book Fair 2019's 'How to Get Ahead in Publishing' seminar. KO's increasing symbolic capital is also reflected in their acquisitions: one of their novelists, Jason Reynolds, was previously a National Book Awards finalist, demonstrating that authors (and indeed literary agents) do not always sign with the largest, most economically powerful publishers. Symbolic capital is clearly a key inspiration of KO's activity. However, as a business they are, of course, also striving to increase their economic capital, as shown by their successful mission over Christmas 2018 to crowdfund $£_{30}$ ooo to found an inclusive children's bookshop. Establishing a bookshop cannot be contained by either economic or symbolic motivation; KO's ethos as a small independent publisher is to genuinely make a difference with respect to diversity in children's fiction, and founding a bookshop will help marginalized children find themselves in fiction-and will also bring in profit for KO. There are indeed 'practices and motivations too varied to be accommodated by a rigid, dualist division between art for the sake of art and art for the sake of money' (Zimbler, 2009, p. 617); KO's activity demonstrates that Bourdieu's strict division is not always illuminating.

A further example of a positive development in diversity in children's fiction, and publishers' ability to combine forms of capital, is American author Angie Thomas's YA novel The Hate U Give (THUG). Published in Britain by Walker Books in February 2017, THUG covers racist police brutality and the Black Lives Matter movement. Its culturally powerful content and phenomenally successful sales demonstrate significant symbolic and economic capital.

Thomas was originally 'far from convinced that she would find a publisher', for the same sorts of reasons highlighted by Blackman: agents 'were telling [Thomas] that books with black kids on the cover don't sell' (Noble, 2018). However, two years after a 13-way publishers' auction, THUG has sold over 850 ooo copies and spent over two years on the New York Times bestseller list (Kantor, 2018) — with a 'black kid' on the cover. As well as economic capital from book sales (and a successful film adaptation), the book's reception demonstrates its accumulated symbolic prestige: it won the 2018 Chartered Institute of Library and Information Professionals Amnesty Award, and 'many are calling it the defining book of a generation' (Noble, 2018). Walker Books can count themselves among 'those who know how to reckon and deal with the "economic" constraints inscribed in this denied economy ... able fully to reap symbolic and even "economic" profits on their symbolic investments' (Bourdieu, 1996, p. 149). Walker's investment in THUG's symbolic value, including its political and social justice themes, has reaped rewards with the prestige bestowed by awards and the successful conversion into economic capital accrued through book sales. Bourdieu acknowledges the combination of symbolic and economic capital: 'the accumulation of symbolic capital ... [is] a veritable credit, and capable of assuring, under certain conditions and in the long term, 'economic' profits' (1996, p. 142). However, his qualification that this effect will occur in the long term is not always true: Thomas's second novel, On the Come Up, has automatic symbolic capital owing to Thomas's now established and 
influential author brand, and on publication in March 2019 instantly became number one in the New York Times bestseller chart (New York Times, 2019).

Although combinations of symbolic and economic capital are powerful and frequent, it is not true that one type always leads to the other; they are not always caught up in the process of 'intraconversion' that James English acknowledges (2002, p. 126). James Daunt, Waterstones' managing director, suggests that, although THUG was initially sold and marketed as a YA book, 'there is no upper [age] limit to being stunned by beautiful writing of this visceral power' (Eyre, 2018). THUG is primarily associated with the YA market but supposedly has cultural power and appeal across readerships (the novel features with a different cover design on adult fiction display tables in bookshops)—but, though the writing may transcend age groups, this is not mirrored by transcendent symbolic or economic capital. THUG has not been nominated for any adult prizes (which would give the book symbolic capital in the adult arena) and its position as a bestseller has always been on children's/YA charts (demonstrating lack of economic capital in the adult market). Daunt's statement that Thomas's writing has potential to stun readers of varied ages is not reflected in the economic or cultural capital the book has gained overall.

\section{Peritext emphasizing symbolic and economic value}

Discussing books that could achieve both strong sales and symbolic capital, Thompson suggests that 'all too often the criteria diverge' (2010, p. 10). THUG is, overall, an important counter-example of this. In the children's market it enjoys economic and cultural success, and, in addition to the book's content and reception, its peritext (the physical product, including its textual and imagebased elements) demonstrates how both economic and cultural motivations were behind many of Walker Books' production decisions. Examination of THUG's peritext may also illuminate the prevalence of diversity in children's publishing.

Peritextual elements often have dual purposes: achieving publicity strategies (with the goal of accruing economic capital) and emphasizing the content's importance (hoping to increase symbolic value). For the emphasis of symbolic content, THUG's cover and preface are the most important. Multiple editions have been published, but the initial British and American covers, as well as the film tie-in edition, feature a black teenage girl. This is paramount for the book's cultural significance; both Thomas and Blackman have discussed the rarity of seeing children's books with black characters on the cover. Peritexts can convey multiple discourses; a prominent discourse on THUG's cover is that this is a culturally potent novel, centred on characters from groups who are too often marginalized. Further cultural importance is signified by peritext at the beginning of the book in the form of a letter from Thomas to readers. This acts as a preface, which Gerard Genette argues 'has as its chief function to ensure that the text is read properly' (1997, p. 197, original emphasis). Thomas tells readers, using direct address, about the importance of activism: 'Art is activism. Writing is activism. Find your activism and don't let anyone tell you what that should look like' (Thomas, 2017, p. i). 'Authors often have a fairly specific idea of the kind of reader they want, or the kind they know they can reach' (Genette, 1997, p. 212): it is evident that Thomas wants to reach passionate young people dedicated to making a difference. Thomas also writes that, 'When you make your voice heard, we're gonna be even louder on your behalf. We've got you. I promise we do' (2017, p. i), showing exactly how the preface can be 'no longer precisely a matter of attracting the reader [as they are already holding the book] ... but of hanging onto [them] with a typically rhetorical apparatus of persuasion' (Genette, 1997, p. 198), since Thomas makes the reader feel she truly cares about them. The preface can express an author's 'statement of intent' (Genette, 1997, p. 221); Thomas's intent through her letter and THUG's plot and themes is clearly to inspire readers to stand up for social justice.

Further peritextual elements focus more on driving sales, although they do often increase the book's symbolic capital, too-showing again that these forms of capital can be effectively combined. Editions of THUG with 'Exclusive Collector's Edition' emblazoned on the cover give the book a special, almost elite feeling, increasing its desirability among readers who want to be one of the select few owners. An endorsement from internationally bestselling YA author John Green declares THUG 'stunning', enhancing the book's reputation, and perhaps thereby its sales, through its association with such a successful author. The inside cover of THUG lists accolades the book has won, including number one New York Times bestseller, New York Times Editor's Choice, 
and the fact the book has been sold in over 25 languages. In this case it is true that 'the fringe of the printed text ... controls one's whole reading' (Lejeune quoted in Genette, 1997, p. 1): these endorsements influence readers' perception of THUG as worthy, valuable, and successful before they even read the first page of the story. The interdependency of symbolic and economic capital invested in and accrued by THUG demonstrates how effective the publication of inclusive children's fiction can be, and illustrates how Bourdieu's 'idealised opposition between the purists and profiteers' (McDonald, 1997, p. 14) misses some of the nuances and overlaps of publishing intentions.

\section{Authorial representation in British YA}

These developments in children's fiction are positive in terms of representation. However, the literary field remains, as Bourdieu (1996) posits, dynamic, with unstable hierarchies. $\mathrm{KO}$ and Thomas are exceptions to the rule of underrepresentation. As Children's Laureate, Blackman was vocal about the lack of ethnic diversity among characters and writers in British fiction; a report by Melanie Ramdarshan Bold (2018) on the representation of YA authors of different ethnic backgrounds between 2006 and 2016 confirmed the lack of inclusion.

From 2006 to 2016, a mere eight per cent of unique YA titles published in Britain (excluding republished editions such as film tie-ins) were written by authors of colour (Ramdarshan Bold, 2018, p. 397). YA novels, 'especially bestselling YA, typically feature protagonists who are white or ethnically ambiguous [and] cisgender' (Ramdarshan Bold, 2018, p. 392); this is mirrored by the published authors, who are predominantly white, cisgender females. Ramdarshan Bold's study also showed that 'authors of colour were more likely to publish with conglomerates, and less likely to self-publish and publish with independent publishers, than their white counterparts' (Ramdarshan Bold, 2018, p. 400). The establishment of $\mathrm{KO}$ is a positive development since the report was published: an independent publisher with the confidence and ability to publish diverse authors.

The overwhelming lack of representation occurs not only in the wide field of published authors but translates on to bestseller lists, too. Of the top 20 bestselling YA titles published in the UK between 2006 and 2016, only one was written by an author of colour: Noughts and Crosses by Malorie Blackman (Ramdarshan Bold, 2018, p. 401). In the children's/YA bestseller chart for the week ending 23 March 2019, there are only two titles written by non-white authors: The Boy at the Back of the Class by Onjali Raúf-which won the Waterstones Children's Book Prize on 21 March (accruing significant symbolic capital, which will be mirrored by an increase in sales and economic capital) — and Nought Forever, a World Book Day title by Malorie Blackman (The Bookseller, 2019). Most of the list consists of wealthy white authors such as J. K. Rowling and David Walliams, who have multiple titles in the bestseller chart most weeks. The lack of diverse authorial representation mirrors the underrepresentation of diverse fictional characters in children's fiction; inclusivity is a problem in both the fictional and real worlds.

The situation can be seen to be improving slightly since the period of Ramdarshan Bold's report: in Britain, 2017's bestselling YA title was Everything, Everything by Jamaican-American author Nicola Yoon; THUG was the second-bestselling YA book of 2018 and in third place was Children of Blood and Bone by Nigerian-American author Tomi Adeyami (Eyre, 2019). However, despite these books' symbolic and economic success, there has not been widespread systemic change in the publishing industry to reflect the increasing awareness of diversity enforced by initiatives and conferences. Factors contributing to this include 'structural inequalities, unconscious biases in the publishing industry ... and (ironically) the lack of author role models' (Ramdarshan Bold, 2018, p. 404). This shows that the symbolism of publishing diversity initiatives (hashtags such as \#ReadTheOnePercent and Diversity and Inclusivity Grants organized by the Booksellers Association) have not, overall, translated into real economic and symbolic capital invested and/or received by publishers. Ramdarshan Bold's report recommends that 'the publishing industry needs to engage in more sustainable action, rather than discussions, to help shift the entire publishing culture' (2018, p. 404) towards being a more reflective industry, bolstering the symbolism of panel discussions and hashtags with concrete investment from publishers in publishing diverse voices and stories. Both the cultural and commercial spheres need to be shifted by these sorts of investments - the phenomenal symbolic and economic success of THUG shows that success is possible-and it is vital, and logically necessary, that these spheres combine in action. 


\section{Conclusion: a future of combinations for all nations}

John Guillory opposes the binary opposition of economic and symbolic capital, pointing out that 'playing the literary game to win in no way cancels the work of making art as an expression "for the love of art"' (1997, p. 397); working in publishing with the aim of creating a commercially successful book does not negate the possibility you can simultaneously intend to publish a meaningful, symbolically and culturally potent book. Angie Thomas's THUG shows young adults the reality of racism and the potency of social justice in America; Walker Books saw this symbolic potential (proven by the fact they submitted THUG for awards that the book went on to win)but, as a larger corporate publisher, they also intended the book to be very successful economically and did reap financial rewards from sales influenced by winning or getting shortlisted for awards. Bourdieu argues that it is 'impossible to account for the structure and functioning of the social world unless one reintroduces capital in all its forms and not solely in the one form recognized by economic theory' (2011, p. 78 ); this is true, and the coexisting motivations of accruing capital in multiple forms must also be acknowledged. To fully understand the social world we live in, we must consider and understand different forms of capital, including economic and symbolic capital; they must all overlap-and this must happen not merely in the real world, but also in written fiction based on this real world, and in the production of this fiction by publishers.

Choices and combinations-multiplicity-are crucial, and what we crave in stories: Pride 'and' Prejudice; The Lion, The Witch 'and' the Wardrobe; Noughts 'and' Crosses. Stories are combinations of experiences; the readership of children's books is a combination of different sorts of readers, and different types of capital must be combined to create powerful books for children. By breaking free from notions of singularity and limits, and

\section{Ethical and commercial motivations}

can be honoured together; publishing a

book because it will sell and publishing

a book because it is the right thing to do

are not mutually exclusive aims. acknowledging that publishing economically successful art and art for art's sake can be coexisting motivations, the publishing industry can nourish a diversity of writers, develop inclusive fictional worlds, and publish inclusive books. Ethical and commercial motivations can be honoured together; publishing a book because it will sell and publishing a book because it is the right thing to do are not mutually exclusive aims.

From a moral perspective, it is obvious that children should be able to see themselves and others reflected in the books they read, in order to learn and grow. CLPE's report on representation stated that 'in the current sociopolitical and economic climate the risk of marginalization of minority groups is heightened. If in their formative years, children do not see their realities reflected in the world around them ... the impact can be tremendously damaging' (2018, p. 9). Books are one of the most powerful ways this damage can be limited. From a narrow business perspective, too, inclusivity is imperative: the wider the range of authors and stories a publisher represents, the wider market they have the potential to attract. Furthermore, Blackman has suggested that the underrepresentation of ethnic minorities in children's fiction can discourage marginalized children from reading, and from writing books themselves (Green, 2014). If this situation does not improve, the publishing field could suffer a lack of renewal of capital and, devastatingly from both an economic and symbolic perspective, perhaps deprive the world of the next generation's Angie Thomas or Aimée Felone.

In children's fiction, it is not just white characters' experiences that matter. Similarly, it is not just economic or symbolic capital that matters. Both types of capital are significant, and they are most effective for publishers when they are combined. Strength comes from combinations-professionals in children's publishing must work together to counter structural inequalities in the industry, create inclusive fiction for children, and invest economic and symbolic capital in these products. Readers do want to buy diverse fiction: THUG's success, KO's growing prestige and economic viability, and the presence on bestseller lists of some books that foreground ethnic diversity prove this. Books reflect reality but they can also actively influence it. The growth of inclusive fiction in which BAME children are the heroes has the potential to lead us closer to a world where no young black girl is told-in a book or in real life-that 'black people become secretaries' (Peacock, 2014). 


\section{References}

Blake, Q., 2019. 'Letter from a Laureate: Quentin Blake', BookTrust

The Bookseller, 2019. 'Top 20 Children's and Young Adult Fiction-23 March, 2019', 23 March

Bourdieu, P., 1996. 'The Market for Symbolic Goods', in The Rules of Art: Genesis and Structure of the Literary Field, trans. S. Emanuel (London: Polity Press)

Bourdieu, P., 2011. 'The Forms of Capital', in The Sociology of Economic Life, ed. M. Granovetter and R. Swedberg, 78-92 (Abingdon: Taylor \& Francis)

CLPE, 2018. Reflecting Realities: A survey of ethnic representation within UK children's literature 2017 (London)

Coats, L., 2014. 'Interview: Malorie Blackman', Publishing Talk, 6, pp. 6-8

English, J., 2002. 'Winning the Culture Game: Prizes, awards and the rules of art', New Literary History, 33 (1), pp. 109-135

Eyre, C., 2018. 'Angie Thomas Wins Waterstones Children's Book Prize', The Bookseller, 22 March

Eyre, C., 2019. 'Crowded Market, Poor Retailing and "Worthy Books" Fall Behind in YA Sales', The Bookseller, 8 February

Genette, G., 1997. Paratexts: Thresholds of interpretation (Cambridge: Cambridge University Press)

Green, C., 2014. 'Children's Books Are Too White, Says Laureate', The Independent, 13 July

Guillory, J., 1997. 'Bourdieu's Refusal'. Modern Language Quarterly. $5^{8}(4)$, pp. $367-398$
Kantor, E., 2018. 'Children's Institute 2018: Angie Thomas urges booksellers to "change the world", Publishers Weekly, 26 June

McDonald, P., 1997. British Literary Culture and Publishing Practice 1880-1914 (Cambridge: Cambridge University Press)

McMaster, R., 2013. 'Why Read?', English Studies in Canada. 39 (2-3), pp. $43^{-61}$

New York Times, 2019. 'Young Adult Hardcover', 24 February

Noble, F., 2018. 'Angie Thomas: Kids like us don't often get discussed', The Bookseller, 24 April

Peacock, L., 2014. "Black people don't become teachers": The racist careers advice Malorie Blackman ignored', The Telegraph, 4 April

Ramdarshan Bold, M., 2018. 'The Eight Per Cent Problem: Authors of colour in the British young adult market (20062016)', Publishing Research Quarterly, 34 (3), pp. 305-406

Thomas, A., 2017. The Hate U Give (London: Walker Books)

Thompson, J., 2010. Merchants of Culture: The publishing business in the twenty-first century (Cambridge: Polity Press)

Walker, 2019. 'Flights of Fancy', 7 February

Ward, V., 2013. 'Black Characters Put Parents off Books, New Children's Laureate Says', The Telegraph, 4 June

Zimbler, J., 2009. 'For Neither Love Nor Money: The place of political art in Pierre Bourdieu's literary field', Textual Practice, $23,599-620$ 